\title{
Geographical Work at the Boundaries of Climate Change
}

\author{
Mike Hulme \\ School of Environmental Sciences, UEA, Norwich \\ m.hulme@uea.ac.uk
}

Viewpoint article submitted to Transactions of the Institute of British Geographers

Draft 24 September 2007

Revised, 2 October 2007

Final version 4 October 2007

\section{Introduction}

The relationship between climate and society has been dynamic throughout human history and pre-history, a relationship that has been variously elemental, creative and fearful. The relationship has now taken a more intimate turn. Human actions, globally aggregated, are changing the composition of the atmosphere which alters the functioning of the climate system. Future climates will not be like past climates. We have often worried about this possibility and now the knowledge claims of science have offered new reasons to be concerned. Humanity is now firmly embedded within the functioning of the climate system, whilst at the same time the idea of climate change is penetrating and changing society in novel ways. The past (through historic emissions of greenhouse gases) and the future (through descriptions of climates to come) are interacting in new ways to provide a novel motor for cultural change. This is all happening under the symbolism of global warming.

Yet the construction of narratives around global warming remain strongly tied to roots within the natural sciences, to expectations of improving 'predictions' and to a problem-solution policy framing which claims both global reach and universal authority. The European Union policy goal of restricting global warming to no more than $2^{\circ} \mathrm{C}$ above nineteenth century global temperature is seemingly powerful, yet fundamentally fragile: powerful because it traces its lineage to positivist and predictive sciences; fragile because it is largely a construction of elite Western minds. This constructed policy goal 
is unlikely to be one around which the world will be re-engineered willingly. Neither positivist science nor Western (neo-)liberalism seem likely to retain global hegemony.

The emergent phenomenon of climate change - understood here simultaneously as physical transformation and cultural object, as a mutating hybrid entity in which the strained lines between the natural and the cultural are dissolving - therefore needs a new examination. And this re-examination must have a different starting point from that arrived at in the twentieth century. Those origins were to be found in the scientific disciplines of the natural sciences and in the institutional process of the Intergovernmental Panel on Climate Change (IPCC), a process whose outcomes rapidly came to dominate climate change discourse. They still do. Instead, our reexamination of climate change today needs to start with contributions from the interpretative humanities and social sciences, married to a critical reading of the natural sciences, and informed by a spatially contingent view of knowledge (e.g. Pettenger, 2007).

The questions that should guide this re-examination include these: What does climate mean to different people and to diverse cultures? Which of these meanings are threatened by climate change and which can co-evolve with a changing climate? How robust is our putative knowledge of future climate? What language is used to portray climatic risks? Is climate change really a collective action problem? Who gains from driving forward ideas of global climate governance? And, in the end, what is our vision of the global future? Who speaks for the twenty-second century? The answers to many of these questions are answers to which geographers should contribute. Shy of intellectually owning climate because of the shame of past determinist ideologies (see Skaggs, 2004), the society of geographers needs now to re-embrace the idea of climate.

I am writing this essay as a geographer who has become detached from the discipline over a 20 year career working at the heart of the climate change knowledge community, close to the circuits of policy. Yet I am troubled by what I have observed happen to climate change. I am increasingly convinced that making human sense of climate change needs the distinctive intuition and skills of the geographer. These intuitions include long familiarity with working at the boundaries between nature and culture (e.g. Petts et al., 2007), a tradition of understanding the subtleties of how knowledge, power and scale are inseparable (e.g. Cox, 1997), and the more recent unveiling (e.g. Livingstone, 2003;

Powell, 2007) that the geography of science is every bit as important as its history. We need new ways of thinking about and understanding the hybrid phenomenon of climate change. Geographers have a unique role to play in this task. 
The essay will suggest three fluid boundaries surrounding climate change at which geographical work could fruitfully be located. The first of these is the important project to reclaim climate from the natural sciences and to treat it unambiguously as a manifestation of both Nature and Culture, to assert that the idea of climate can only be understood when its physical dimensions are allowed to be interpreted by their cultural meanings. The second project, contingent on the first, is to reveal that discourses about global climate change have to be re-invented as discourses about local weather and about the relationships between weather and local physical objects and cultural practises. Climate change knowledge and meaning travels uncomfortably across scales and needs constant re-interpretation as it is applied in different spatial contexts. The third project is to examine critically the knowledge about climate change captured by the various assessments of the IPCC and to understand the various ways in which this knowledge is situated. The IPCC assessments exert considerable hegemony over climate change policy debates and yet insights from the geography of science can tell us a lot about how (un)stable and particular is such knowledge.

\section{Reconnecting culture with climate}

The framing of climate change that remains dominant in contemporary scientific and public policy discourse was shaped crucially during the period from 1985 to 1992 . The WMO/UNEP/ICSU Villach Conference of November 1985 established the hegemony of the natural sciences in the way climate change would subsequently be presented to the policy world. This framing led directly to the establishment in 1988 of the IPCC under the auspicies of the WMO and UNEP (Miller, 2004). Through its first Assessment Report of 1990 the IPCC staked out the contours of climate change - almost trade-marked Climate Change $^{\mathrm{TM}}$ one might say - which were to dominate the next two decades. It certainly had an imposing effect with respect to the inter-governmental negotiations which led in 1992 to the signing of the UN Framework Convention on Climate Change. The Convention, supplemented by the Kyoto Protocol in 1997, remains today the benchmark for all climate policy discourse, a benchmark bolstered by the knowledge claims in subsequent reports from the IPCC in 1995, 2001 and 2007.

The three key elements of this framing were: a globalised atmosphere - 'an ontologically unitary whole’ (Miller, 2004) which offered to the world a single depository for greenhouse gas emissions and which opened the way for predictive climate modelling; the goal of a stabilised global climate as the centerpiece of policy (Boykoff et al., submitted, a); and the institutionalising of mitigation and adaptation as co-dependents 
in future global climate policy regimes.

Insights from the social sciences, and from geography in particular, were notably absent from this early framing. The considered contributions from a social science perspective - most notably Rayner and Malone (1998) and Miller and Edwards (2001) - came along too late to re-mould the framework despite attempts to do so (e.g. Sarewitz \& Pielke, 2000).

The consequences of this history remain with us today. Arguably (e.g. Sarewitz, 2004), they are one of the reasons why progress towards meeting stated climate change policy goals is so tortuous. Climate is defined in purely physical terms, constructed from meteorological observations, predicted inside the software of Earth system science models and governed (or not) through multilateral agreements and institutions. What is sought to be stabilized is a quantity - global temperature, or its proxy carbon dioxide concentration - a quantity wholly disembodied from its multiple and contradictory cultural meanings. Future climates are predicted and, whether these predictions are read rhetorically or literally, they depend tenuously - at best - on ideas and possibilities of future cultural change.

Yet there is another, orthogonal reading of climate which has been suppressed in this contemporary framing of climate change. Masterfully narrated by Clarence Glacken in his 1967 'Traces of a Rhodian
Shore', climate can also be understood as an imaginative idea, an idea constructed and endowed with meaning and value through cultural activity. A few more recent voices have been raised in praise of such a reading, the voices of cultural historians, historians of science and anthropologists; thus books about climate and culture by Meyer (2000), Strauss and Orlove (2003), Boia (2005), Cruikshank (2005), Fine (2007) and Golinksi (2007). Registers of climate can be read in memory, behaviour, text and identity as much as they can be measured through meteorology, as Golinski shows in his enlightened survey of eighteenth century British attitudes to weather and climate: “... this ... view of the climate was bound up with the sense of British national identity” (2007:57). Of these voices, however, few have been geographers.

So why do we persist with this dualistic account of climate as nonoverlapping physical and cultural entities? Are we content with this 'purification' of climate, a purification that Latour (1993) claims is constitutive of modernism? My claim in this essay is that the answer is 'no' and that geographical work can help bring these two orthogonal readings of climate into a more creative alignment. This does not merely imply siren calls for greater inter-disciplinarity in climate change research institutions or funding. It implies something deeper than this. The subject to be studied - climate - needs to be re-framed through negotiating a different 
ontological and epistemological structuring of climate knowledge (cf. Petts et al., 2007). This intellectual re-framing of climate has to take place before one considers the methods, tools and institutions which would then need to be deployed.

If we are to show the multitudinous ways in which climate and culture are connected in places that have a history and in places that have a future then William Meyer's (2000) cultural account of Americans and their weather needs re-writing for multiple ethnicities, networks and nation-states. Lucien Boia's (2005) imaginative history of the idea of climate needs its geographical sibling. Many more of the types of case studies reported in Strauss and Orlove (2003) need completing. By critiquing the geopolitics of the anthropocene, through tackling the triumvirate of globalisation, empire and environment, Simon Dalby (2007) shows glimpses of how a new holistic and critical geography of the natural and the cultural can yield novelty.

\section{Moving climate across scales}

The sterility of a purely physical reading of climate can be illustrated if we consider the movement of statistically-constructed climates across scales. The pre-dominant way of capturing the physicality of climate is through meteorological measurement ${ }^{1}$. By standardizing such measurements and then by

\footnotetext{
1 There are other ways of capturing the physical essence of climate - vegetation, ice cover, soil moisture, etc. - yet these are largely derivative; similar reservations would apply to these descriptors.
}

circulating them through centralised bureaucracies it became possible, first, to quantify (local) weather and subsequently to construct statistical (aggregated) climates. The story of this 'domestication' (Rayner, 2003) of climate through the eighteenth and nineteenth centuries is well-told by, respectively, Golinski (2007) and Anderson (2005). More recently in the twentieth century, these standardized registers of weather have enabled an abstracted 'global climate' - indexed via surface temperature - to be constructed, opening the way for model-based predictions of climate change and fuelling a hubristic discourse about the 'control' of future climate (compare Crutzen, 2006 with Fleming, 2006).

It is important to notice what happens in this circuit of transportation. Weather is first captured locally and quantified, then transported and aggregated into regional and global indicators. These indicators are abstracted and simulated in models before being delivered back to their starting places (locales) in new predictive and sterilised forms. 'Digitised' weather for virtual places can even be conjured from these models using stochastic weather generators. Through this circuitry, weather - and its collective noun climate becomes detached from its original human and cultural setting. A rainstorm which offers an African farmer the visceral experience of wind, dust, thunder, lightening, rain - and all the ensuing social, cultural and economic signifiers of these phenomena - is reduced to a number, say $17.8 \mathrm{~mm}$. This number is propagated into the globalised and universalizing machinery of meteorological and scientific institutions and assessments where it loses its identity. 
There is of course much more to this story, but the point of telling it this way is to show that climates do not travel well between scales: the essential loading of climate with culture - what climate means for people and places and the relationships between people and places over time is completely lost through such purifying practises. This begins to explain one of the paradoxes of the current framing of climate change. On the one hand the physicality of weather is being increasingly influenced by human practises on a global scale - yes, temperatures are rising. Yet the very construction of these universalised diagnostic indicators of change strips them of their constitutive human values and cultural meanings.

As if surprised, much conventional research about climate change is now devoted to finding ways of restoring these lost values and meanings (e.g. Adger et al., in press), to reconnect purified climate indicators with local practices and to re-situate and re-contextualise putative future climates in unique geographical settings (e.g. Wilbanks \& Kates, 1999). This explains the attention given in such circles to the arcane practices of climate model 'down-scaling' and to the growing urgency for understanding adaptive practices and resilient coping strategies. It also explains the late, somewhat sheepish discovery by non-anthropological climate change researchers of local indigenous (climatic) knowledge (e.g. Berkes et al., 2000).

There is much geographical work to be done to repair the damage that has been thus caused. Beyond the advocacy of wider cultural readings of climate (as above), this second area of activity asks geographers to play their full part alongside anthropologists, psychologists, sociologists, literary critics and ecologists - in ensuring local meanings of climate retain their integrity and are more faithfully indexed to the physical dimensions of weather: “... situating [climate change] within a relational context that may include the places people live, their histories, daily lives, cultures or values” (Slocum, 2004:416). Such research is needed as much, perhaps more, in countries of the North and West as in countries of the South and East. Survey after survey has shown that by constructing climate change as a global problem, one that is distanced and un-situated relative to an individual's mental world, we make it easy for citizens to verbalise superficial concern with the problem, but a concern belied by little enthusiasm for behavioural change (e.g. Slocum, 2004; Lorenzoni et al., 2007). By 'de-culturating' climate - i.e., purifying climate and letting it travel across scales detached from its cultural anchors we have contributed to conditions that yield psychological dissonance in individuals: the contradictions between what people say about climate change and how they act (Stoll-Kleeman et al., 2001).

Geographers are well placed to do the imaginative yet meticulous work of revealing the local roots of climate meanings and in then finding ways of allowing climate to travel and cross scales without losing these essential anchors and narratives ${ }^{2}$. The study of Nuie (reported in Adger et al., in press) and the ways in which reactions to climate change and sea-level rise are embedded in much wider stories about the economic, cultural

\footnotetext{
2 This has some similarities to the idea of 'memory mapping' in which writers explore people and places and the relations between them, combining fiction, history, traveller's tales, autobiography, anecdote, aesthetics, antiquarianism, conversation, and memoir (University of Eassex, Maria Warner, www.vam.ac.uk/activ events/adult resources/memory maps
} 
and demographic aspirations of a Pacific island is just one illustration of why universal and globalised constructions of climate will not connect with the local. Jennings' study (2008) of community risk perceptions and climate change discourses in Boscastle in Cornwall, following the floods of 2004, is another. 'The view from no-where' (Shapin, 1998) has no local resonance; climate, and hence climate change, must always be viewed from somewhere. Another example of a geographer at work in this mode is the study by John Thornes (2007) in which he uses visual representations of the atmosphere in the art works Constable, Monet and Eliasson to understand the cultural symbolism of the skies, weather and climate, symbolism which still resonates today in local sub-cultures of western Europe.

\section{Spatial ordering of climate change knowledge}

The third geographical project I propose as urgent is to scrutinise the knowledge claims made by science about climate change, most notably the various assessments of the IPCC. This is part of the bigger project of 'putting science in its place' as argued in David Livingstone's eponymous book. This project that should be undertaken by deploying the insights and tools of the geographer to see how knowledge is spatially produced and consumed and how it travels between sites of production and consumption ... "in the consumption of science, as in its production, a distinctive regionalism manifests itself' (Livingstone, 2003:123).
During its 20 year history, the IPCC has been examined critically from a number of different standpoints: dissecting its 1980s origins (Franz, 1997), revealing its norms, practices and self-governance (Agrawala, 1998), debating the role of consensus its assessments (Demeritt, 2001), and tracing the relationship of its institutional function and knowledge claims to emerging ideas of global environmental governance (Miller, 2004). But other questions remain about the status of climate change knowledge synthesized by the IPCC, questions which emerge from the agendas raised by the new geographers of science (e.g. Powell, 2007). As Sheila Jasanoff has shown in many of her writings (e.g. Jasanoff, 2004; 2005), knowledge that is claimed by its producers to have universal authority is received and interpreted very differently in different political and cultural settings. Revealing the localization and spatialisation of knowledge thus becomes central for understanding both the acceptance and resistance that is shown towards the knowledge claims of the IPCC.

The IPCC presents its reports to the world as the 'consensus view of the leading climate change experts in the world'. But how are the contours of this knowledge shaped? How localized are the sites of climate change knowledge production and how well does this knowledge travel? This is not just about the very small cabal of government scientists and bureaucrats who constitute the IPCC 
governing bureau and who determine the structure and content of the various assessments. Nor is this just about the processes and outcomes by which experts are entrained in the assessment activity. These questions of personnel and their geographical settings should indeed be examined. But there also needs to be attention paid to the peculiarities of the production sites of the primary knowledge assessed: the exclusive network of climate modelling centres that exerts power over descriptions of future climate; the voids on the Earth's surface where few or no observations of climate, phonology or tide variations are made; the digital circuitry and laboratory practices which transform millions of meteorological measurements into (just) a very small number of indices which capture the state of the Earth's climate in a single temperature register. An understanding of the ways in which space modulates these processes of production, and the alternative ways in which this construction process might work, is essential for scrutinising claims of credibility and legitimacy. Some technical self-policing by the IPCC has been undertaken with regard to questions of uncertainty characterization and peer review (e.g. Edwards \& Schneider, 2001), but geographers of science have not yet embarked on a more penetrating analysis.

Geography plays a central role not only in the production of IPCC knowledge, but also crucially in its consumption. The danger here is that uncritical submission to the globalised knowledge claims of an elitist and labyrinthine institution closes down spaces in which the negotiation of politics might get to work. As pointed out earlier, the deeply materialist register in which climate change is currently marked, sucks out from climate most of its rich and culturally diverse significance. As Cathleen Fogel states, '... the global knowledge that the IPCC produces helps governments erect and then justify their simplified constructions of people and nature, and the institutions based on them" (Fogel, 2004:109). But beyond this we need to consider how these impoverished constructions of climate change knowledge are variously consumed in different institutional and cultural settings. What counts as authentic public knowledge in one state, might have much weaker traction within another (Jasanoff, 2004). The consensus science of the IPCC might look persuasive from the centralized sites of production. The views from the peripheries of space, of power and of culture the very places where knowledge is consumed - look very different. We need to understand this story and tell it widely.

\section{Conclusion}

This essay has expressed concern that climate change is not making sense to us: we have universalised the idea of climate, detached it from its cultural settings and failed to read the ways in which the knowledge claims emerging 
from climate science change meaning as they travel. It has argued that geographers have a unique role to play in repairing the damage done - not restoring the physical climate in the literal sense implied by the rhetoric of climate policy, but repairing our idea of what climate means in different places and to different peoples and at different times. By dissolving the strained boundaries between Nature and Culture, by revealing that knowledge and scale are co-dependent, by disclosing the spatial contingencies of climate change knowledge, geographers can offer a different reading of climate change. It will be a reading that is more engaging and human than the one currently on offer.

Why does this matter? It matters because the dominating construction of climate change as an overly physical phenomenon readily allows climate change to be appropriated uncritically in support of an expanding range of ideologies ... of green colonialism (e.g. Agrawal \& Narain, 1991), of the commodification of Nature (e.g. Thornes \& Randall, in press), of natural security (e.g. Sindico, 2007), of celebrity (e.g. Boykoff et al., submitted, b), and many others. These creeds may or may not be undesirable. But the materializing and globalizing properties of the existing framing of climate change - what I call the de-culturating of climate - endow climate change with a near infinite plasticity. Climate change becomes a malleable envoy enlisted in support of too many rulers.
Geographers, as do historians of science (e.g. Latour, 1993) and anthropologists (e.g. Cruikshank, 2005), understand that meaning is lost once the physical and the cultural are cleaved. By purifying climate we de-stabilise the idea of climate, allowing it to be appropriated in support of one-eyed agendas. We cannot allow this to happen. We need first to understand why we disagree about climate change - and we disagree exactly because of the power of the more imaginative perspectives on climate hinted at in this essay before we can put the idea of climate change more assuredly to work in our local, national and international politics. By stripping climate of its flowing cultural and psychological symbolism, by ignoring the multiple meanings of climate, we are in danger of letting the idea of climate change get out of control.

And why does any of this matter for geography and geographers? For too long geographers have forgotten that climate is an idea that emerges from the heart of the discipline - or rather that geography lies at the heart of the idea of climate ${ }^{3}$. Climate is an idea which encapsulates the immersion of the physical with the cultural, in which local and global dynamics interweave and where the memory of the past meets the possibilities of the future ${ }^{4}$. Embarrassed in the first half of the

\footnotetext{
3 The Greek word klima means 'slope' or 'incline' referring to the dependence of incident solar radiation on latitude, a geographical concept.

4 Scott Huler's (2004) philosophical biography of the Beaufort wind-scale, in which science and poetry travel through changing cultures, exemplifies this conception of climate.
} 
twentieth century by the naïve determinists, geographers became increasingly happy to leave climate well alone. Distancing themselves from the idea, climate was left first to the physical geographers, who in turn handed it over to the meteorologists who most recently have been usurped by the Earth system scientists. This distancing has not been helpful. The time is now right to welcome climate back into the intellectual family of geography. Rather than joining in the project to conquer climate, geographers should be announcing a celebration of climate even as we become active agents in its future. Climate and humanity have travelled a long way together; let us not give up now.

\section{Acknowledgements}

This essay would not have been written without conversations with Suraje Dessai, Sarah Dry, Susan Owens, Sam Randalls and Sheila Jasanoff, and without the stimulus of discussions within the Tyndall Centre adaptation team.

\section{References}

Adger,W.N., Barnett,J. and Ellemor,H. (in press) Unique and valued places at risk in, Climate change science and policy (eds.) Schneider,S., Rosencranz,A. and Mastandrea,M., Island Press

Agrawal,A. and Narain,S. (1991) Global warming in an unequal world Centre for Science and the Environment, Delhi, India

Agrawala,S. (1998) Structural and process history of the Intergovernmental Panel on Climate Change Climatic Change 39, 621-642.
Anderson,K. (2005) Predicting the weather: Victorians and the science of meteorology Chicago University Press, 376pp.

Berkes,F., Colding,J. and Folke,C. (2000) Rediscovery of traditional ecological knowledge as adaptive management Ecological Applications 10(5), 1251-1262.

Boia,L. (2005) The weather in the imagination Reaktion Books, London, 200pp.

Boykoff,M.T. and Goodman,M. (submitted, b) Conspicuous redemption? Reflections on the promises and perils of the 'celebritizaton' of climate change Geoforum

Boykoff,M.T., Frame,D. and Randalls,S. (submitted, a) Stabilize this! How the discourse of 'climate stabilization' became and remains entrenched in climate science-policy/practice interactions Annals of the Association of American Geographers

Cox,K.R. (ed.) (1997) Spaces of globalisation: reasserting the power of the local Guildford Press, New York, 292pp.

Cruikshank,J. (2005) Do glaciers listen? Local knowledge, colonial encounters and social imagination UBC Press, Vancouver, 312pp.

Crutzen,P. (2006) Albedo enhancement by stratospheric sulfur injections: a contribution to resolve a policy dilemma Climatic Change 77(3/4), 211-220.

Dalby,S. (2007) Anthropocene geopolitics: globalisation, empire, environment and critique Geography Compass 1(1), 103-118.

Demeritt,D. (2001) The construction of global warming and the politics of science Annals of the Association of American Geographers 91(2), $307-$ 337.

Edwards,P.N. and Schneider,S.H. (2001) Selfgovernance and peer-review in science-for-policy: the case of the IPCC Second Assessment Report pp.219-246 in, Changing the atmosphere: expert knowledge and environmental governance Miller,C. and Edwards,P.N. (eds.), MIT Press, Cambridge MA, 385pp.

Fine,G.A. (2007) Authors of the storm: meteorologists and the culture of prediction University of Chicago Press, 280pp.

Fleming,J.R. (2006) The pathological history of weather and climate modification: three cycles of promise and hype Historical Studies in the Physical and Biological Sciences 37(1), 3-25.

Fogel,C. (2004) The local, the global and the Kyoto Protocol pp.103-126 in, Earthly politics: local and global in environmental governance (eds.) Jasanoff,S. and Martello,M.L., MIT Press, Cambridge, MA, 355pp. 
Franz,W.E. (1997) The development of an international agenda for climate change: connecting science to policy Interim Report IR-97034, IIASA, Laxenburg, 31pp.

Glacken,C. (1967) Traces on the Rhodian Shore: nature and culture in western thought from ancient times to the end of the eighteenth century University of California Press, LA, USA, 763pp.

Golinski,J. (2007) British weather and the climate of enlightenment Chicago University Press, 282pp.

Huler,S. (2004) Defining the wind: the Beaufort scale and how a nineteenth century Admiral turned science into poetry Crown Publishers, New York, 304pp.

Jasanoff,S. (2005) Designs on nature: science and democracy in Europe and the United States Princeton University Press, Princeton/Oxford, 374pp.

Jasanoff,S. (ed.) (2004) States of knowledge: the coproduction of science and the social order Routledge, London, 332pp.

Jennings,T.L. (2008) Adaptation to climate change in the UK: a case study of the Boscastle harbour flood disaster Paper presented at the Tyndall Centre Conference on 'Limits to Adaptation', Royal Geographical Society, London, February 2008.

Latour,B. (1993) We have never been modern (trans.) Harvard University Press, Harvard MA, USA, 168pp.

Livingstone,D.N. (2003) Putting science in its place: geographies of scientific knowledge University of Chicago Press, Chicago, 234pp.

Lorenzoni et al (2007) Lorenzoni,I., Nicholson-Cole,S. and Whitmarsh,L. (2007) Barriers perceived to engaging with climate change among the UK public and their policy implications Global

Environmental Change 17(3/4), 445-459.

Meyer,W.B. (2000) Americans and their weather Oxford University Press, Oxford, 278pp.

Miller,C. and Edwards,P.N. (eds.) (2001) Changing the atmosphere: expert knowledge and environmental governance MIT Press, Cambridge MA, 385pp.

Miller,C.A. (2004) Climate science and the making of a global political order pp.46-66 in, States of knowledge: the co-production of science and the social order (ed.) S.Jasanoff, Routledge, London

Pettenger,M. (2007) The social construction of climate change Ashgate Press, Aldershot, 256pp.

Petts,J., Owens,S. and Bulkley,H. (2007) Crossing boundaries: inter-disciplinarity in the context of urban environments Geoforum doi:10.1016/j.geoforum.2006.02.008
Powell,R.C. (2007) Geographies of science: histories, localities, practises, futures Progress in Human Geography 31(3), 309-329.

Rayner,S. (2003) Domesticating nature: commentary on the anthropological study of weather and climate discourse pp.277-290 in, Weather, climate, culture (eds.) Strauss,S. and Orlove,B., Berg, Oxford, UK, 307pp.

Rayner,S. and Malone,E.L. (eds.) (1998) Human choice and climate change, Volume 1 - the societal framework Batelle Press, Ohio, USA, 491pp.

Sarewitz,D. (2004) How science makes environmental controversies worse Environmental Science and Policy, 7, 385-403.

Sarewitz,D. and Pielke,R.Jr. (2000) Breaking the global-warming gridlock The Atlantic Monthly, 286, 55-64.

Shapin,S. (1998) Placing the view from nowhere: historical and sociological problems in the location of science Transactions of the Institute of British Geographers 23, 5-12.

Sindico,F. (2007) Climate change: a security (council) issue? Carbon \& Climate Law Review 1(1), 2934.

Skaggs,R.H. (2004) Climatology in American geography Annals of the Association of American Geographers 94(3), 446-457.

Slocum,R. (2004) Polar bears and energy-efficient lightbulbs: strategies to bring climate change home Environment \& Planning D: Society and Space, 22, 413-438.

Stoll-Kleeman,S., O’Riordan,T. and Jaeger,C.C. (2001) The psychology of denial concerning climate mitigation measures: evidence from Swiss focus groups Global Environmental Change 11, 107 117.

Strauss,S. and Orlove,B. (eds) (2003) Weather, climate, culture Berg/Oxford International, Oxford, 416pp.

Thornes,J.E. (2007) Cultural climatology and the representation of sky, atmosphere, weather and climate in selected art works of Constable, Monet and Eliasson Geoforum doi:10.1016/j.geoforum.2006.10.015

Thornes,J.E. and Randalls,S. (in press) Commodifying the atmosphere: 'pennies from heaven'? Geografiska Annaler, 89A(5)

Wilbanks,T.J. and Kates,R.W. (1999) Global change in local places: how scale matters Climatic Change 43(3), 601-628. 